\title{
Dido gene expression alterations are implicated in the induction of hematological myeloid neoplasms
}

\author{
Agnes Fütterer, ${ }^{1}$ Miguel R. Campanero, ${ }^{2}$ Esther Leonardo, ${ }^{1}$ Luis M. Criado, ${ }^{1}$ Juana M. Flores, ${ }^{3}$
} Jesús M. Hernández, ${ }^{4}$ Jesús F. San Miguel, ${ }^{4}$ and Carlos Martínez-A ${ }^{1}$

1Department of Immunology and Oncology, Centro Nacional de Biotecnología/Consejo Superior de Investigaciones Científicas, Madrid, Spain. ${ }^{2}$ Instituto de Investigaciones Biomédicas, Consejo Superior de Investigaciones Científicas-Universidad Autónoma de Madrid, Madrid, Spain. ${ }^{3}$ Department of Animal Pathology II, Facultad de Veterinaria, Universidad Complutense de Madrid, Madrid, Spain. ${ }^{4}$ Servicio de Hematologia, Hospital Universitario and Centro de Investigación del Cancer, Universidad de Salamanca, Consejo Superior de Investigaciones Científicas, Salamanca, Spain.

The myelodysplastic/myeloproliferative diseases (MDS/MPDs) are a heterogeneous group of myeloid neoplasms that share characteristics with chronic myeloproliferative diseases and myelodysplastic syndromes. The broad spectrum of clinical manifestations makes MDS/MPDs extremely difficult to diagnose and treat, with a median survival time of 1-5 years. No single gene defect has been firmly associated with MDS/MPDs, and no animal models have been developed for these diseases. The association of deletions on chromosome $20 \mathrm{q}$ with myeloid malignancies suggests the presence of unidentified tumor suppressor genes in this region. Here we show that the recently identified death inducer-obliterator (Dido) gene gives rise to at least 3 polypeptides (Dido1, Dido2, and Dido3) through alternative splicing, and we map the human gene to the long arm of chromosome 20. We found that targeting of murine Dido caused a transplantable disease whose symptoms and signs suggested MDS/MPDs. Furthermore, $100 \%$ of human MDS/MPD patients analyzed showed Dido expression abnormalities, which we also found in other myeloid but not lymphoid neoplasms or in healthy donors. Our findings suggest that Dido might be one of the tumor suppressor genes at chromosome $20 \mathrm{q}$ and that the Dido-targeted mouse may be a suitable model for studying MDS/MPD diseases and testing new approaches to their diagnosis and treatment.

\section{Introduction}

Myelodysplastic syndromes (MDSs), chronic myeloproliferative diseases (CMPDs), and myelodysplastic/myeloproliferative diseases (MDS/MPDs) are 3 different, heterogeneous groups of clonal hematopoietic stem cell disorders that are distinguished by a combination of morphological, immunophenotypic, genetic, and clinical characteristics $(1,2)$. Both inefficient hematopoiesis, which causes cytopenia, and disordered (dysplastic) maturation of 1 or more myeloid cell lines are characteristic of MDSs (3). In contrast, CMPDs are characterized by efficient hematopoiesis, which results in increased numbers of granulocytes, red blood cells, and/ or platelets in peripheral blood (4); nonetheless, bone marrow failure and ineffective hematopoiesis can be found in late CMPD stages as a consequence of marrow fibrosis (5-7). MDS/MPDs are characterized by both proliferative and dysplastic manifestations at initial presentation and are therefore difficult to assign to the myelodysplastic or myeloproliferative neoplasm groups. Prolifera-

Nonstandard abbreviations used: aCML, atypical chronic myeloid leukemia; AML, acute myeloblastic leukemia; BAC, bacterial artificial chromosome; BFU-E, burst forming unit-erythrocyte; CFU-GM, CFU-granulocyte-macrophage; CLL, chronic lymphocytic leukemia; CML, chronic myeloid leukemia; CMML, chronic myelomonocytic leukemia; CMPD, chronic myeloproliferative disease; CT, cycle threshold(s); Dido1, death inducer-obliterator 1 (also known as DIO-1); hDido, human Dido; JMML, juvenile myelomonocytic leukemia; $m$ Dido2, murine Dido2; MDS, myelodysplastic syndrome; MDS/MPD, myelodysplastic/myeloproliferative disease; MEF, mouse embryonic fibroblasts; NLS, nuclear localization signal; RACE, rapid amplification of cDNA ends; SPA-1, signal-induced proliferation-associated gene 1.

Conflict of interest: The authors have declared that no conflict of interest exists.

Citation for this article: J. Clin. Invest. 115:2351-2362 (2005).

doi:10.1172/JCI24177. tion of 1 or more myeloid lineages is frequently very efficient and may lead to leukocytosis; however, cells may be morphologically and functionally dysplastic (8). Simultaneously, proliferation of other lineages may be ineffective, resulting in cytopenia (2). Hematopoietic progenitor cells from MDS/MPD and MDS patients but not from CMPD patients often show decreased colony/cluster ratios (9-11). Splenomegaly is commonly found in MDS/MPD and CMPD patients but rarely in those with MDSs $(12,13)$. Differential diagnosis among Philadelphia-negative CMPD, MDS, and MDS/MPD patients is often difficult, as there are cases that evolve from MDSs to CMPDs but also others that evolve in the opposite direction, from CMPDs to MDSs (14-17). According to the classification recently proposed by the World Health Organization, 4 diseases have been assigned to the MDS/MPD category; these are (a) chronic myelomonocytic leukemia (CMML), the most frequent form of MDS/MPD; (b) atypical chronic myeloid leukemia (aCML); (c) juvenile myelomonocytic leukemia (JMML); and (d) unclassifiable MDS/MPD $(1,2)$.

Considerable effort is being made to classify mouse hematopoietic neoplasms that can readily be compared with the World Health Organization classification. The proposed classification of mouse nonlymphoid hematopoietic neoplasms includes categories for nonlymphoid leukemias, nonlymphoid hematopoietic sarcomas, myeloid dysplasias, and myeloid proliferation (18); gaps in this classification correspond to human diseases that have not been described in mice. This is the case for human MDS/MPDs, as no mouse disorder in the nonlymphoid hematopoietic neoplasm category displays myelodysplastic and proliferative features simultaneously. 

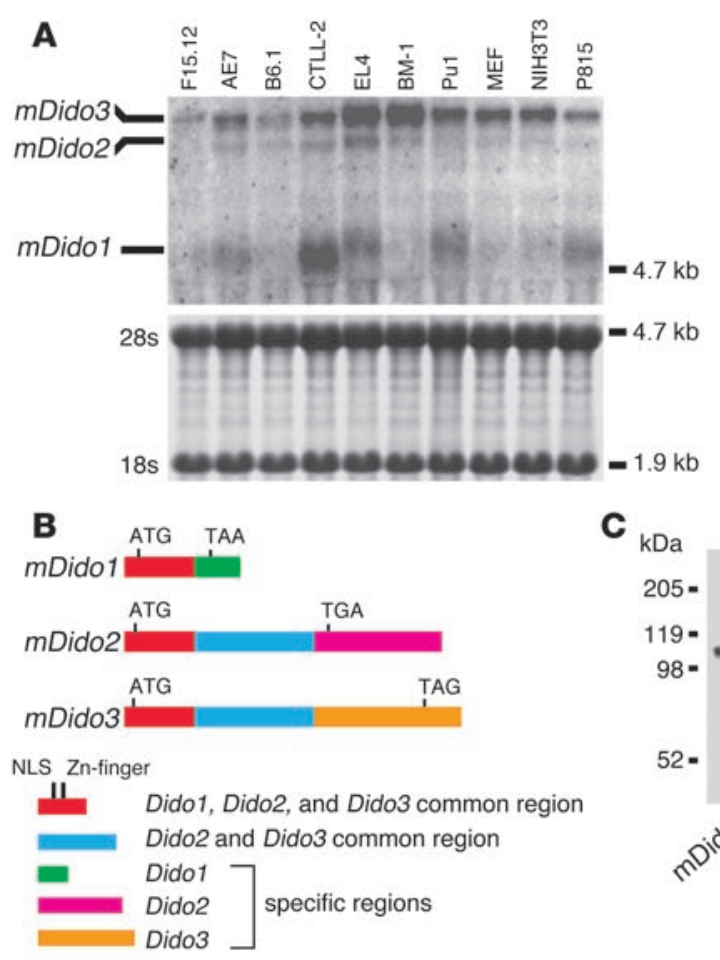

C $_{\mathrm{kDa}}$
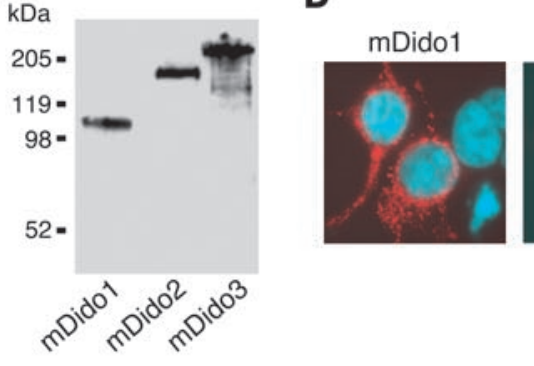

D

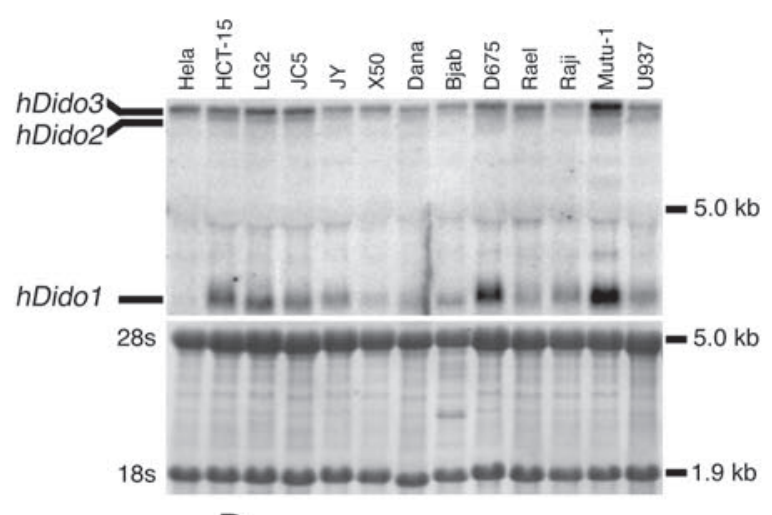

Figure 1

Cloning of 2 novel Dido transcripts. (A) Dido transcript expression was analyzed in murine (left) and human (right) cell lines by hybridization with a probe corresponding to full-length Dido1. Blots were stained with methylene blue to normalize the amounts loaded. (B) Schematic representation of Dido1, Dido2, and Dido3. Different colors indicate common and specific nucleotide sequences. (C and D) Flag-tagged Dido1, Dido2, and Dido3 expression was analyzed in immunoblot (C) or immunofluorescence (D) of transfected 293T cells using anti-Flag M2 mAb. Molecular size markers are indicated at left $(\mathbf{C})$. Magnification, $\times 100$.

Several recurring chromosomal and molecular abnormalities are associated with specific myeloid disorders. This is the case for chronic myelogenous leukemia, for which the $B C R / A B L$ fusion gene allows unequivocal diagnosis and provides a likely mechanism of pathogenesis (19). Deletion of the long arm of chromosome 20 is the second most common structural abnormality in patients with hematological neoplasms (20). This anomaly is found recurrently in CMPDs, MDSs, and acute myeloblastic leukemia (AML) patients but is rarely seen in lymphoid malignancies $(21,22)$; it is also described in some MDS/MPD patients and patients with CMPDs in transition to MDSs $(10,21,23)$. Association of deletions on chromosome $20 \mathrm{q}$ with these myeloid malignancies suggests the presence of 1 or more tumor suppressor genes in the long arm of chromosome 20; loss or inactivation of these genes is thought to perturb regulation of multipotent hematopoietic progenitors through yet unknown mechanisms.

No specific genetic defects have been identified for any of the entities included in the MDS/MPD group. Regulation defects of the Ras pathway are found in some CMML, aCML, and JMML patients, but abnormalities in this pathway alone do not lead to MDS/MPD disorders; other mechanisms must interact with these molecular defects to produce the abnormal kinetics observed in patients with MDS/ MPDs. In addition, deregulation of the Ras pathway in the mouse causes diseases that mimic CMPDs but not MDS/MPDs (24-27). To date, no animal model has been developed for MDS/MPDs.

A differential display approach was used to identify death inducer-obliterator 1 (DIO-1; also known as Dido1 and DATF) as a gene whose expression is upregulated early in apoptosis (28). Its predicted amino acid sequence comprises a glutamine-rich region, an acidic sequence, and a canonical bipartite nuclear localization signal (NLS) in the $\mathrm{N}$ terminal region, $2 \mathrm{Zn}$-finger motifs in the central region, and a $\mathrm{C}$ terminal lysine-rich sequence (28). Here we report the cloning of 2 additional human and murine Dido isoforms that result from alternative splicing of the same gene. We mapped the human gene to the long arm of chromosome 20 and now show its involvement in the induction of human and mouse myeloid hematological malignancies. The Dido-targeted mouse may be an appropriate model for studying MDS/MPDs and may allow new approaches in the diagnosis and treatment of these pathologies.

\section{Results}

Dido2 and Dido3 cDNA cloning. Northern blot analysis of human and murine Dido1 expression showed 3 different transcripts in most cell lines and tissues analyzed (Figure 1A), the smallest of which was previously identified as DIO-1 (28). To identify the 2 larger transcripts, we searched the National Center for Biotechnology Information (NCBI) database for known nucleotide sequences similar to that of Dido1 and found a human clone (KIAA0333) whose 5' but not $3^{\prime}$ end sequence was identical to that of the human Dido1 (bDido1) nucleotide (not shown). Rapid amplification of $3^{\prime}$-cDNA ends ( $3^{\prime}$-RACE) with primers for sequences common to $b$ Dido1 and KIAA0333 generated 3 different clones with identical 5' but different $3^{\prime}$ ends (not shown). These results suggested the existence of 
3 Dido transcripts, referred to hereafter as $h D i d o 1, b D i d o 2$ (the fulllength version of KIAA0333), and hDido3.

Full-length hDido2 and hDido3 cDNA were generated by RTPCR on mRNA from the Mutu-1 human B lymphocyte line using primers for sequences upstream of $h D i d o 1$ start and downstream of $h$ Dido 2 and $h$ Dido 3 stop codons. Using mRNA from another human B cell line (JY), we obtained independent hDido2 and hDido3 cDNA clones, which rendered nucleotide sequences iden- tical to those derived from Mutu-1. Full-length murine Dido2 and Dido3 (mDido2 and mDido3) cDNA were generated by RT-PCR on mRNA from brain tissue and from the FL5.12 B lymphocyte line. Regions common to the 3 Dido proteins, common only to Dido2 and Dido3, and specific for each protein are depicted in Figure 1B. mDido 2 and $\mathrm{mDido} 3 \mathrm{cDNA}$ sequencing indicated strong similarity in the coding region to hDido 2 and hDido $3 \mathrm{cDNA}$, respectively (not shown). The overall degree of identity between human and

$\begin{array}{lll}\text { mDido3 } & 1 & \text { MDDKGHLSNEEAPKAIKPTSKEFRKTWGFRRTTIAKREGAGDTEVDPSEQQPQQHNLSLRRSGRQPKRTERVEEFLTTVRRRGKKNVPVSLEDSSEPTSS } \\ \text { mDido2 } & 1 \text { MDDKGHLSNEEAPKAIKPTSKEFRKTWGFRRTTIAKREGAGDTEVDPSEQQPQQHNLSLRRSGRQPKRTERVEEFLTTVRRRGKKNVPVSLEDSSEPTSS } \\ \text { mDido1 } & 1 \text { MDDKGHLSNEEAPKAIKPTSKEFRKTWGFRRTTIAKREGAGDTEADPSEQQPQQHNLSLRRSGRQPKRTERVEEFLTTVRRRGKKNVPSLEDSSEPTSS }\end{array}$

mDido3 101 TVTDVETASEGSVESSSEIRSGPVSDSLGKEHPASSEKAKGGEEEEDTSDSDSDGLTLKEIQNRLRRKREQEPVERSLRGS PNRLRKKRREEDSAETGSV mDido2 101 TVTDVETASEGSVESSSEIRSGPVSDSLGKEHPASSEKAKGGEEEEDTSDSDSDGLTLKEI QNRLRRKREQE PVERSLRGSQNRLRKKRREEDSAETGSV mDido1 101 TVTDVETASEGSVESSSEIRSGPVSDSLGKEHPASSEKAKGGEEEEDTSDSDSDGLTLKELQNRLRRKREQEPVERSLRGSENRLRKKRR EEDSAETGSV

mDido3 201 QIGSAEQDRPLCKQEPEASQGPVSQSETDDIENQLEGKATQGNTEENPREAGKPKPECEVYDPNALYCICRQPHNNRFMICCDRCEEWFHGDCVGISEAR mDido2 201 QIGSAEQDRPLCKQEPEASQGPVSQSETDDIENQLEGKATQGNTEENPREAGKPKPECEVYDPNAL Y CICRQPHNNRFMICCDRCEEW HGDCVGISEAR mDido1 201 QIGSAEQDRPLCKQEPEASQGPVSQSETDDIENQLEGKATQGNTEENPREAGKPKPECEVYDPNALYCICRQPHNNRFMICCDRCEWH HGDCVGISEAR

mDido3 301 GRLLERNGEDYICPNCILQVQDETNGSATDEQDSGCRSVGADGTDCTSIGTVEQKSGEDQGIKGRIEKAANPSGKKKLKIFQPVVEAPGAPKCIGPGCS mDido2 301 GRLLERNGEDYICPNCILQVQDETNGSATDEQDSGCRSVGADGTDCTSIGTVEQKSGEDQGIKGRIEKAANPSGKKKLKIFQPVVEAPGAPKCIGPGCS mDido1 301 GRLLERNGEDYICPNCIILQVDETNGSATNEQDSGCRSVGADGTDCTSIGTVEQKSGEDQGIKGRIEKAANPSGKKKLKIFQPVVEAPGAPKCIGPGCS

mDido3 401 SVAQPDSVYCSNDCILKHAAATMRFLSSGKEQKTKPKEKVKTKPEKFSLPKCSVQVGIKISSVHKRLASEKRENPVKKVMLASRSETSGKEAACESSTPS mDido2 401 SVAQPDSVYCSNDCILKHAAATMRFLSSGKEOKTKPKEKVKTKPEKFSLPKCSVQVGIKISSVHKRLASEKRENPVKKVMLASRSETSGKEAACESSTPS mDido1 401 SVAQPDSVYCSNDCILKHAAATMRFLSSGKEQKTKPKEKVKTKPEKFSLPKCSVQVGIKISSVHKRLASEKRENPVKKVMLASRSETSGKEAACESSTPS $\star$

mDido3 501 WASDHNYNAVKPEKPEKPTALSPTLLSKSMKDDRRVEDRTMAAVTIPKKALPSASLVGRQTSPRNLVPKKLPPYSNMAGAKPAIKKLPSGFKGTIPKRPW mDido2 501 WASDHNYNAVKPEKPEKPTALSPTLLSKSMKDDRRVEDRTMAAVTI PKKALPSASLVGRQTSPRNLVPKKLPPYSNMAGAKPAIKKLPSGFKGTIPKRPW mDido1 501 WASDHNYNAVKPEKPEKPTALSPTLLSKCTYHPKAGFPGPSHHLGGCLGLSRTRVLGVLVLIVASSSLPARSRYQDASGPQVFLPSLWSLSGWFLKSCVG

mDido3 601 PSATLSGTSARQAGPTPMTAASKKLPGSAAVVGVTRKPMSANVPAASPAPGRLGPVSPAPSQPNSQIRQNIRRSLKEILWKRVNDSDYLIMTENEVGKIA mDido2 601 PSATLSGTSARQAGPTPMTAASKKLPGSAAVVGVTRKPMSANVPAASPAPGRLGPVSPAPSQPNSQIRQNIRRSLKEILWKRVNDSDYLIMTENEVGKIA mDido1 601 LMLEAISYFSFRPW

mDido3 701 LHIEKEMFNLFQVTDNRFKSKYRSIMFNLKDPKNQGLFHRVLREEISLAKLVRMKPEELVSKELSMWTEKPTKSVIESRTKLLNESKKNTTKPETIPDME mDido2 701 LHIEKEMFNLFQVTDNRFKSKYRSIMFNLKDPKNQGLFHRVLREEISLAKLVRMKPEELVSKELSMWTEKPTKSVIESRTKLLNESKKNTTKPETIPDME

mDido3 801 DSPPVSDSEEQQESVRAAPEKSAAPLLDVFSSMLKDTTSQHRAHLFDLNCKICTGQVPSSEDEPAPKKQKLSASSKKEDFKPRHDSSPPNAVPNTADEGI mDido2 801 DSPPVSDSEEQQESVRAAPEKSAAPLLDVFSSMLKDTTSQHRAHLFDLNCKICTGQVPSSEDEPAPKKQKLSASSKKEDFKPRHDSSPPNAVPNTADEGI

mDido3 901 ADTLPENASEPDPESTSSLNQERKCFPESPGDSHPEPSSLGGLSPSSASGGSGVVTTVTMSGRDPRTALSGSCTVTASMAAHLDNSQASETKLDMIKPAL mDido2 901 ADTLPENASEPDPESTSSLNQERKCFPESPGDSHPEPSSLGGLSPSSASGGSGVVTTVTMSGRDPRTALSGSCTVTASMAAHLDNSQASETKLDMIKPAL

mDido3 1001 TSAVVPKSILAKPSSSPDPRYLSVPPSPSISESRSPPEGDTTLFLSRLNTIWKGFINMQSVAKFVTKAYPVSGCLDYLSEDLPDTIHIGGRIAPKTVWDY mDido2 1001 TSAVVPKSILAKPSSSPDPRYLSVPPSPSISESRSPPEGDTTLFLSRLNTIWKGFINMQSVAKFVTKAYPVSGCLDYLSEDLPDTIHIGGRIAPKTVWDY

mDido3 1101 VGKLKSSVSKELCLIRFHPATEEEEVAYISLYSYFSSRGRFGVVANNNRHVKDLYLIPLSAKDPVPSKLLPFEGPGLESPRPNI ILGLVICOKVKRPSSA mDido2 1101 VGKLKSSVSKELCLIRFHPATEEEEVAYISLYSYFSSRGRFGVVANNNRHVKDLYLIPLSAKDPVPSKLLPFEGPGKHPVSGR

mDido3 1201 GELDKTDEKRTRLQQEELETSVYPKVTAALPSEKKPPKYSVHSIDTAATSTTPPGSPPPPPPLPEPPVLKILSSLKPGSTSTVTAPTTAAITTTASPVTA mDido3 1301 ATSKTASPLEHILQTLFGKKKSFEPSGKESVGSTLSPHQDSKAKGEDTMSAAPLLDPIVQQFGQFSKDKALEEEEEDDRPYDPEEEYNPDRAFHTLLAEP mDido3 1401 GRPHDVQSVSETAEREEVAYDPEDETILEEAKVTIDDLPNRMCMKVSATERPADFTTDASSASLVEQQKMLEELNKQIEEQKRQLEEQEEALRQQRAAVG mDido3 1501 VSMAHFSVSDALMSPPPKSSLGKTELFSOEOOAPDPSOGAPNTNHNLDSROSRDPROARRLAAENTENESLPRAPTGSTPGPOGTLPARETPAGTAVVOG mDido3 1601 PGLAAEAKESMAVPWAPGENAVLRPEHDIQKCEHPGNPVSLPLDTSHLPTAGDGAARPAPPRRVLLPTPSTTFPPSFPLQPKAQNFSSGSREPFSGPTF mDido3 1701 MSQETSLGSSYYEPRGAQSAGKNDSPVADMEDSREPQLRPGESTTSFPQPGQRGGGPQPQFPGQREPAPRTFGMSGHHGPSFPGPRGPVPPYSEENLVP mDido3 1801 NSDGPRGPPPARFGAQKPPIPSLFSGQHGPPPYGDNRGLSPSYLGGPRGGAPAQFEDRKDPHGEKREFQDTPYNEMTGAPAOCEGPDQAOFMGNRAPFOF mDido3 1901 GGQRRPLLTQMKGPRGGPPPSQFGAQRGPPPGHFVGPRGPHPSQFENSRGTHPGQFEGARGQAPGFMPGPRGIQPQQFEEQRVNSPPRFAGQRASAPLPY mDido3 2001 GGPRGPAPFPEKNEQPPSRFHFQGPSSQPVKPPPRPLLELPSHPPHHRTDRWDKAGPPTALPSSAGPGQGHEADGQWATSEFREGKGHEYRSPAFEGRQR mDido3 2101 ERFEAGSKEKPLDEPEAQGLESRQGRAFEDRRRERERGRNWSRERDWERSRDWDRHREWDKGRDRSSNRDRERDNDRAKEWDRSRERSRNRDRDRERRRD mDido3 2201 RDRSRSRDRDRDRERARDRDRDRGRDRKDRSKSRESPRDQKPEARTSEGGPAAAQA

\section{Figure 2}

Alignment of murine Dido1, Dido2, and Dido3 predicted amino acid sequences. Boxes indicate the bipartite NLS sequence (black), Zn-finger domains (blue), and TFS2M domains (green). The asterisk at M423 indicates the first available ATG codon in truncated Dido3. 


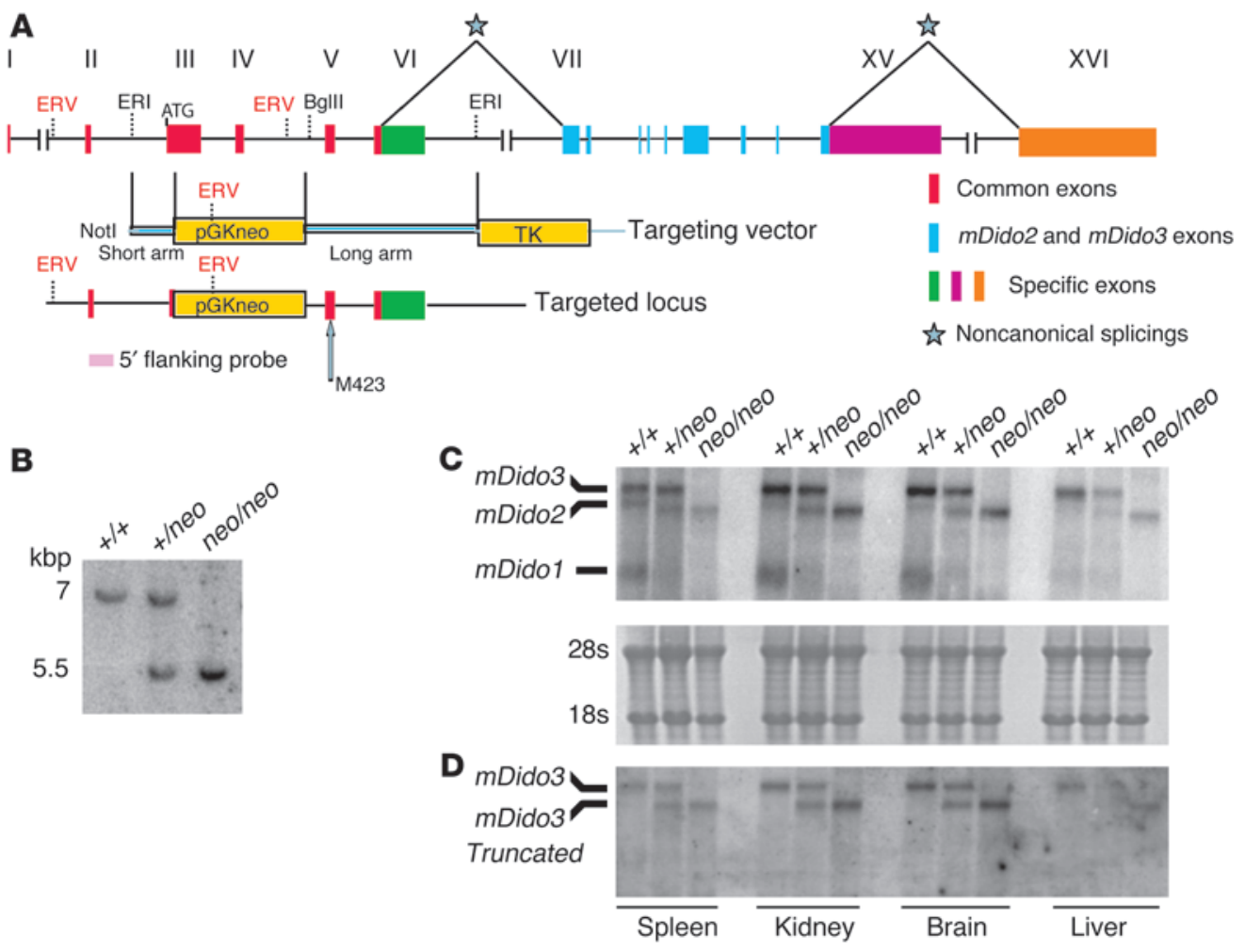

Figure 3

Targeted disruption of the mDido locus. (A) Scheme showing exon-intron structure of the Dido locus. Colors indicate common and specific nucleotide sequences. Noncanonical splicing events are indicated with stars. To target the murine Dido locus, a region containing exon IV and most of exon III was deleted and replaced by a neoresistance cassette. A restriction map is shown of WT mouse Dido. Arrow indicates the position of M423. ERV, EcoRV; ERI, EcoRI. (B) Southern blot hybridization. Mouse Dido disruption by homologous recombination resulted in a 5.5-kb band using EcoRV-digested genomic DNA. (C) mDido transcript expression was analyzed in WT (+/+), Dido ${ }^{+/ n e o}(+/$ neo $)$, and Dido ${ }^{\text {neo/neo }}($ neo/neo) mouse tissues by hybridization with a probe common to the $3 \mathrm{mDido}$ transcripts. The blot was stained with methylene blue to control RNA loading. (D) mDido3 transcript expression was analyzed on the same blot with an mDido3-specific probe.

mDido1. The strategy for generation and identification of mice with targeted disruption in Dido is shown in Figure 3A. $m$ Dido-targeted mice in which both gene copies had been disrupted were identified by Southern blot of tail DNA (Figure 3B). Northern blot of total RNA prepared from several mouse tissues confirmed that Didoneo/neo cells lacked mDido1 and mDido2 mRNA (Figure 3C) but retained a short mDido3 mRNA that migrates faster than mDido2, as confirmed with an mDido3specific probe (Figure 3D). A shorter mDido3 protein was detected in Didoneo/neo than in $\mathrm{Dido}^{+/+}$cells (not shown). cDNA sequencing showed that this transcript lacked exons III and IV, indicating that the original translation start signal was absent. The short mDido3 protein thus had to be initiated at an ATG codon in exon $\mathrm{V}$ or a downstream exon; the earliest ATG available for translation start in truncated mDido3 is M423 (see Figures 2 and 3A).

Didoneo/neo mice were born at the predicted Mendelian frequency, appeared grossly normal, and had no anatomic

mouse Dido2 and Dido3 proteins was $77.8 \%$ and $73.1 \%$, respectively. mDido 2 and mDido 3 cDNA encoded 1183 and 2256 amino acid proteins that were expressed in human embryonic kidney 293 cells (Figure 1C). mDido1 localizes in the cytosol, whereas both mDido 2 and $\mathrm{mDido} 3$ are found in the nucleus (Figure 1D), suggesting different roles for Dido1 and the other isoforms. mDido1, mDido2, and mDido3 amino acid sequence alignment is shown in Figure 2.

Human and murine Dido genomic loci were organized similarly and contained 16 exons whose alternative splicing generated the 3 Dido polypeptides (Figure 3A). Consensus splice sites were present at all exon-intron boundaries. Splicing nonetheless appeared to take place at noncanonical sites to generate the Dido1 to Dido2 (exon VI to exon VII) and Dido2 to Dido3 (exon XV to exon XVI) transitions (Figure 3A). Karyotypic analysis and an NCBI database search showed that the bDido loci map to human chromosome $20 \mathrm{q} 13.33$ whereas those in mice map to the syntenic chromosome 2H4 (not shown).

Targeting of murine Dido causes a disease similar to human MDS/MPD. To establish the physiological role of the mDido gene in vivo, we disrupted a region of the mDido locus containing exons common to the 3 isoforms and harboring the glutamine-rich region, the acidic sequences, and the NLS and Zn-finger motifs described for or behavioral abnormalities at 1 month of age. Fertility of male and female Didoneo/neo mice was severely reduced (van Wely et al., unpublished observations). By 7 to 8 months of age, some Dido $o^{+/ n e o}$ and Dido ${ }^{\text {neo/neo }}$ mice showed clear symptoms of disease. Examination of organs revealed that spleen, bone marrow, or both were affected severely but heterogeneously. Spleens of $73 \%$ of diseased Dido-targeted mice were enlarged compared with those of healthy Dido-targeted mice (12\%) or of wild-type controls (7\%) (Figure 4C). Average spleen weight for wild-type mice was $0.18 \mathrm{~g}( \pm 0.07)$ whereas that of diseased Dido ${ }^{+/ n e o}$ and Dido ${ }^{\text {neo } / \text { neo }}$ mice was more than $0.3 \mathrm{~g}$ for most individuals (Figure 4C and Table 1). The increase in white pulp of some diseased mice was such that spleen architecture was destroyed (Figure 4A). Some cells from these spleens also had atypical nuclei, characteristic of dysplastic cells (Figure 4B). CD3positive (T lymphocyte) and B220-positive (B lymphocyte) cells are the most abundant populations in normal spleens, whereas monocytic (CD11b-positive/GR1-negative), granulocytic (CD11b/GR1double positive), and erythroid (Ter119-positive) cells account for a minority of splenocytes. Flow cytometry analysis of splenocytes from diseased mice revealed distinct abnormality patterns compared with analysis of control splenocytes. Some affected animals (such as C28) showed increases in the number of spleen granulocytes, monocytes, and erythroid cells; other diseased mice (such as 
A
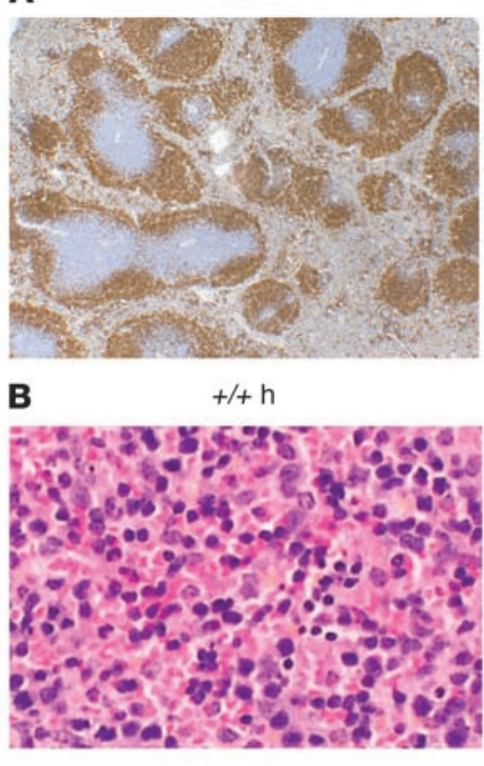

C

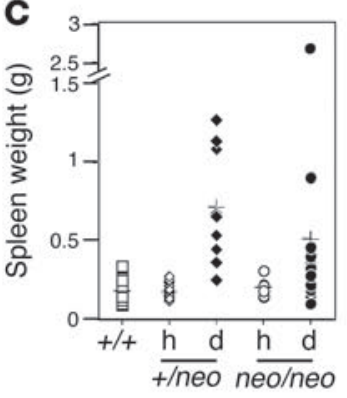

D
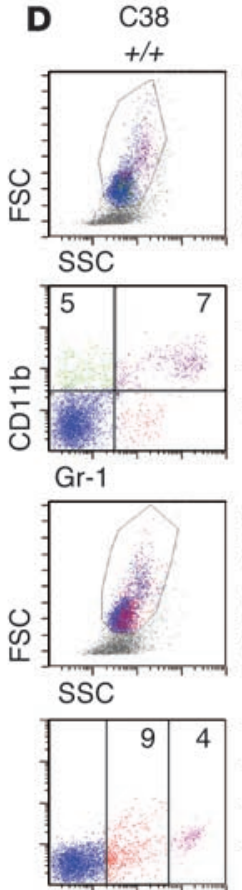

Ter119

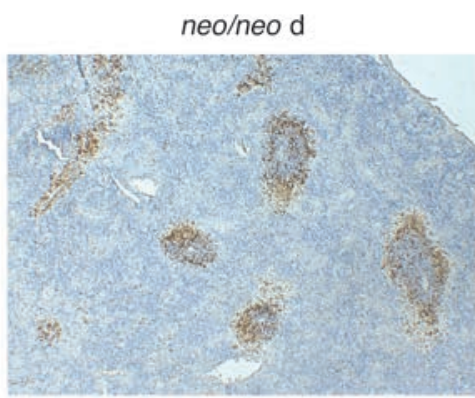

neo/neo d
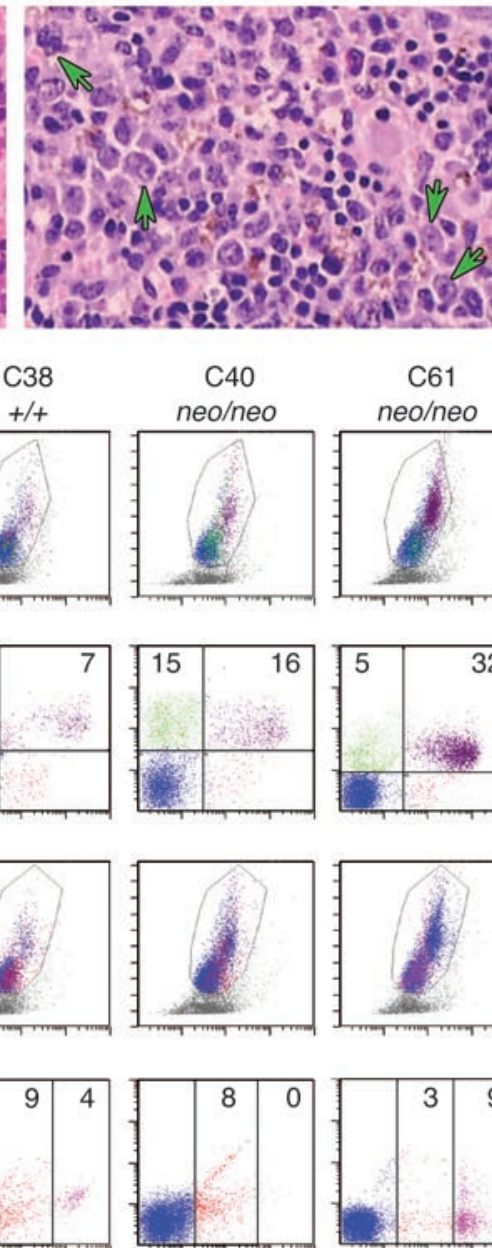

0
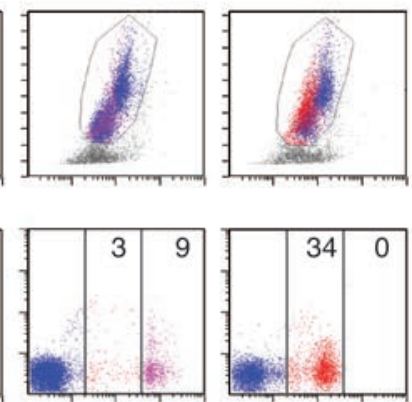

\section{Figure 4}

$A$ variety of lesions are found in spleens of affected Dido-targeted mice. (A) Spleen sections from WT and diseased Dido $^{\text {neo/neo }}$ mice were immunostained with anti-B220 mAb and hematoxylin-counterstained. $h$, healthy; $d$, diseased. (B) Spleen sections from WT and diseased Dido ${ }^{\text {neo/neo }}$ mice were H\&E stained. Note the abundance of myeloid cells with atypical nuclei (arrows). Magnification, $\times 6$ (A); ×20 (B). (C) Spleen weight of WT, healthy, and diseased Dido $^{+/ \text {neo }}$ and Dido neo/neo mice. (D) Flow cytometry analysis of splenocytes from WT (C38) and diseased Dido ${ }^{\text {neolneo }}$ (C28, $\mathrm{C} 40$, and C61) mice stained with mAbs against CD11b, Gr-1, Ter119, and control antigens. Forward scatter (FSC) versus side scatter (SSC), CD11b versus Gr-1, and Ter119 versus control dot plots are shown. Numbers in boxes indicate percentages of cells within each gate.

marrow, we screened bone marrow for alterations in cell composition. Flow cytometry analysis showed that some affected $D_{i d o}^{+/ n e o}$ and Dido neo/neo mice (such as C28) had a marked increase in marrow granulocyte numbers whereas others (such as C40) showed an increased marrow monocytic population concomitant with a decreased percentage of mature erythroid progenitors (Ter119-bright cells) (Figure 5A and Table 1). Analysis of other markers, such as Sca1, c-kit, CD41, and CD34, showed no evident differences between healthy and affected mice (not shown). The percentage of blasts, determined by morphology in bone marrow smears, was not notably increased in the marrow of diseased mice (between $4 \%$ and $14 \%$ of all nucleated cells). The marrow of some diseased mice had large numbers of megakaryocytes and some cells with atypical nuclei (Figure 5B).

C40) showed notably increased spleen monocyte and granulocyte numbers, and some (such as C61) had an increased granulocyte population (Figure 4D and Table 1 and not shown). The size/ complexity pattern of Ter119-positive cells in mice with erythroid alterations was indicative of the presence of erythrocytic progenitors in the spleen. These erythroid cells were Ter119-dim rather than bright (see C28 in Figure 4D), indicating immature progenitors. These lesions were frequently but not always associated with splenomegaly (Table 1), suggesting a diagnosis of MDS/MPD.

In situ TUNEL assays on spleen showed no notable differences in apoptosis among genotypes (not shown), suggesting that splenomegaly was not caused by defects in apoptosis. As spleen enlargement is often a consequence of defective hematopoiesis in bone
The abnormalities observed in myeloid and erythroid lineages led us to assess the in vitro growth of marrow granulocyte-macrophage and erythrocyte progenitors (CFU-granulocyte-macrophage [CFU-GM] and burst-forming unit-erythrocyte [BFU-E] assays, respectively). Simply scoring the numbers of CFU-GM and BFU-E is of limited value in MDS diagnosis $(9,11)$, although significant differences in these values might indicate an alternative diagnosis. We scored the overall number of colonies plus clusters and found that it was similar in all mouse genotypes (not shown), as is the reduction in colony/cluster ratios between MDS/MPD patients compared with healthy individuals is thus helpful in diagnosing patients with MDS and MDS/MPD $(9,11)$. Marrow granulocytecase for MDS/MPD patients and healthy individuals (10). The 
Table 1

Representative sample of lesion heterogeneity in diseased Dido-targeted mice

\begin{tabular}{|c|c|c|c|c|c|c|c|c|c|c|c|c|c|c|}
\hline & \multirow{2}{*}{$\begin{array}{c}\text { WT } \\
\text { mean } \pm \text { SD }\end{array}$} & \multicolumn{3}{|c|}{ t/neo } & \multicolumn{10}{|c|}{ neo/neo } \\
\hline & & B94 & C1 & C14 & B90 & C4 & C12 & C16 & C19 & C28 & C40 & C60 & C61 & C62 \\
\hline \multicolumn{15}{|l|}{ Bone marrow } \\
\hline \multirow[t]{2}{*}{ Low colony formation ${ }^{A}$} & $2.4 \pm 0.75$ & 1.0 & 0.6 & 1.7 & 2.4 & 0.4 & 2.3 & 0.8 & ND & 1.3 & 0.2 & 1.5 & 1.9 & 0.6 \\
\hline & $2.1 \pm 1.25$ & 1.8 & 0.7 & 1.7 & 1.2 & 1.0 & 1.5 & 0.8 & ND & 1.1 & 0.3 & 0.7 & 2.1 & 1.3 \\
\hline Monocytosis ${ }^{B}$ & $1.9 \pm 0.8$ & 1.8 & 10.1 & 0.4 & 2.9 & 1.9 & 3.7 & 3.2 & 2.1 & 7.3 & 24.0 & 1.9 & 3.1 & 5.6 \\
\hline Granulocytosis ${ }^{\mathrm{C}}$ & $43.7 \pm 16.1$ & 65.5 & 16.6 & 90.9 & 33.1 & 64.9 & 45.4 & 41.7 & 73.9 & 71.7 & 48.0 & 63.1 & 64.8 & 40.5 \\
\hline Ab. erythropoiesis ${ }^{D}$ & $34.9 \pm 11$ & 26.5 & 49.2 & 6.7 & 42.3 & 17.7 & 28.7 & 49.7 & 17.2 & 25.9 & 22.0 & 23.8 & 10.2 & 22.6 \\
\hline \multicolumn{15}{|l|}{ Spleen } \\
\hline SplenomegalyE & $0.18 \pm 0.07$ & 0.25 & 1.13 & 1.08 & 0.46 & 0.22 & 0.40 & 0.32 & 0.41 & 0.90 & 0.19 & 0.29 & 0.35 & 0.34 \\
\hline Monocytosis ${ }^{B}$ & $5.5 \pm 1.9$ & 3.6 & 10.5 & 1.1 & 9.0 & 5.1 & 4.4 & 12.8 & 2.5 & 11.5 & 18.0 & 7.8 & 9.6 & 7.8 \\
\hline Granulocytosis ${ }^{\mathrm{C}}$ & $12.3 \pm 8.1$ & 34.2 & 15.2 & 57.1 & 14.4 & 20.1 & 20.4 & 22.1 & 47.6 & 32.6 & 13.0 & 26.9 & 31.5 & 17.1 \\
\hline ErythrocytosisF & $13.5 \pm 6.7$ & 5.4 & 13.3 & 25.4 & 6.5 & 19.7 & 17.1 & 15.9 & 23.7 & 32.4 & 8.0 & 13.6 & 11.1 & 7.6 \\
\hline \multicolumn{15}{|l|}{ Blood } \\
\hline \multirow[t]{2}{*}{ Anemia ${ }^{\mathrm{G}}$} & $11.6 \pm 0.8$ & 10.5 & 7.2 & 9.4 & 11.3 & 13.0 & 10.9 & 11.1 & 11.4 & 9.7 & 8.4 & 11.0 & 10.1 & 11.8 \\
\hline & $160 \pm 14$ & 134 & 128 & 116 & 146 & 167 & 154 & 163 & 140 & 109 & 126 & 152 & 144 & 164 \\
\hline Monocytosis ${ }^{H}$ & $0.5 \pm 0.2$ & 1.4 & 0.7 & 4.2 & 0.6 & 0.8 & 0.1 & 0.7 & 0.7 & 2.1 & 0.5 & 0.3 & 0.9 & 0.2 \\
\hline Granulocytosis ${ }^{H}$ & $2.1 \pm 1.4$ & 5.2 & 17.7 & 30.3 & 1.6 & 2.9 & 1.3 & 1.8 & 12.2 & 21.9 & 1.6 & 2.2 & 3.3 & 2.9 \\
\hline
\end{tabular}

Mouse codes and genotypes are shown at top; values in red indicate lesions in each mouse. Values for WT mice ( $n=15)$ are mean \pm SD. Ab, abnormal; ND, not determined. ACFU-GM (top line) and/or BFU-E (bottom line) colony/cluster ratios were 50\% lower than in WT mice. ${ }^{B}$ Percentage of monocytes in indicated organs was at least $50 \%$ higher than in WT mice. CPercentage of granulocytes in indicated organs was at least 50\% higher than in WT mice. DTer119positive cells were at least 30\% lower than in WT mice, or Ter119-bright cells were absent (C40). ESpleen weight was at least $50 \%$ higher than in WT mice. FPercentage of Ter119-positive cells in spleen was at least $50 \%$ higher than in WT mice. GErythrocyte number was less than $10 \times 10^{12} / \mathrm{I}$ (top line), and hemoglobin levels were less than $130 \mathrm{~g} / \mathrm{l}$ (bottom line). ${ }^{\mathrm{H}}$ Monocyte number was greater than $1 \times 10^{9} / \mathrm{l}$ and granulocyte number was greater than $7 \times 10^{9} / \mathrm{l}$.

macrophage and erythrocyte progenitors from WT mice gave rise to more colonies than clusters, whereas a larger number of clusters than of colonies was observed in marrow progenitor cells from most diseased Dido $o^{+/ n e o}$ and Didoneo/neo mice (Figure 5C and Table 1). Hematopoietic progenitors from diseased Dido-targeted mice thus showed an abnormal growth pattern, similar to that observed in intermediate MDS/MPD disease. These results support a diagnosis of MDS/MPD for affected Dido-targeted mice.

Peripheral blood from diseased mice was analyzed in a hematocytometer and indicated that $47.8 \%$ showed anemia (decreased red blood cell counts and decreased hemoglobin levels), $21.7 \%$ displayed leukocytosis (>16 $\left.\times 10^{9} / 1\right), 17.4 \%$ presented monocytosis $\left(>10^{9} / 1\right)$, and $26.1 \%$ exhibited granulocytosis $\left(>7 \times 10^{9} / 1\right)$. Platelet count was highly variable, even among WT mice (not shown). This hematological profile is compatible with MDS/MPDs.

Our data indicated abnormalities in spleen, bone marrow, and peripheral blood of diseased Dido ${ }^{+/ \text {neo }}$ and Dido neo/neo mice. Lesions included various combinations of symptoms characteristic of myeloid dysplasia or myeloid proliferation, including (a) abnormal levels of erythroid, granulocytic, or monocytic cells in spleen and/or bone marrow; (b) large numbers of dysplastic cells in spleen and/or bone marrow; (c) splenomegaly; (d) decreased colony formation accompanied by increased cluster formation potential of cultured granulocyte-macrophage and erythroid progenitors; (e) anemia; and (f) monocytosis or granulocytosis in peripheral blood (Table 1). This combination of myeloproliferative and dysplastic features is not found in any of the murine nonlymphoid hematopoietic neoplasms reported to date. These symptoms are nonetheless similar to those described for MDS/MPD patients and suggest a diagnosis of MDS/MPDs for diseased Dido-targeted mice. For statistical purposes, we considered only mice showing 3 or more spleen and bone marrow lesions to have developed MDS/MPDs.
Although both $D_{i d o^{+/ n e o}}$ and Didoneo/neo mice showed a greater predisposition to MDS/MPDs than WT mice, Dido neo/neo mice were much more likely to develop disease (Figure 6). In total, 9 of 86 $\mathrm{Dido}^{+/ \text {neo }}$ and 17 of $38 \mathrm{Dido}^{\text {nеo/neo }}$ mice were diagnosed with MDS/ MPDs. In accordance with a gene-dosage effect, expression of the only mDido transcripts detectable in Dido ${ }^{+/ n e o}$ mice (full-length and truncated $m D i d o 3$ ) was not lost in affected heterozygous mice (see Supplemental Figure 1; available online with this article; doi:10.1172/JCI24177DS1).

Targeting of murine Dido causes a transplantable disease. To test whether the disorder in Dido-targeted mice was an intrinsic property of their cells, bone marrow cells from healthy $\mathrm{Dido}^{+/+}$or diseased Dido nеo/nеo mice were transplanted into lethally irradiated $\mathrm{Dido}^{+/+}$ mice. Spleen, bone marrow, and blood from surviving healthy and affected recipients were screened for MDS/MPD symptoms. All recipients of marrow cells from diseased animals but no recipients of normal mouse marrow cells, developed 3 or more MDS/ MPD-related symptoms (Table 2), meeting our diagnostic criteria for MDS/MPDs. Some mice (A1, B1, and E2) reconstituted with bone marrow cells from a $\mathrm{Dido}^{+/+}$mouse developed mild spleen erythrocytosis $(40.3 \%, 37.4 \%$, and $24.8 \%$ spleen erythrocytes respectively), which was accompanied by moderate anemia in mouse A1 $\left(9.32 \times 10^{12} \mathrm{red}\right.$ blood cells/1; $126 \mathrm{~g}$ hemoglobin/l). In contrast, mice $\mathrm{C} 1$ and $\mathrm{C} 2$ developed severe spleen erythrocytosis $(84.2 \%$ and $79.6 \%$ spleen erythrocytes, respectively) and severe anemia (4.66 and $5.57 \times 10^{12}$ red blood cells/1; $67 \mathrm{~g}$ and 89 g hemoglobin/l, respectively). The results suggest that symptoms observed in mouse A1 reflect an irradiation reaction rather than MDS/MPDs. Mice D1, D2, and F1 also showed mild spleen erythrocytosis, but in contrast to mouse A1, they developed additional severe MDS/ MPD symptoms (Table 2). Together, our data strongly suggest that the disease in Dido-targeted mice is transplantable. 
A
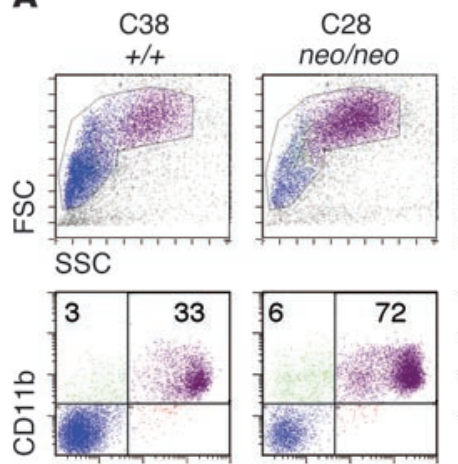

$$
\text { Gr-1 }
$$

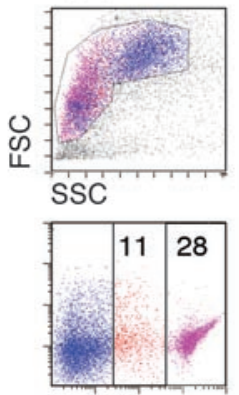

Ter119
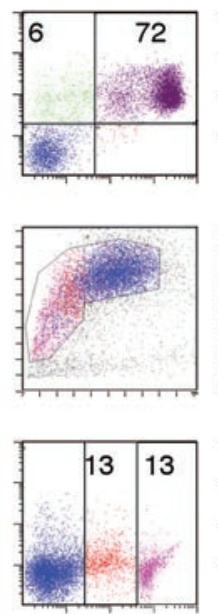
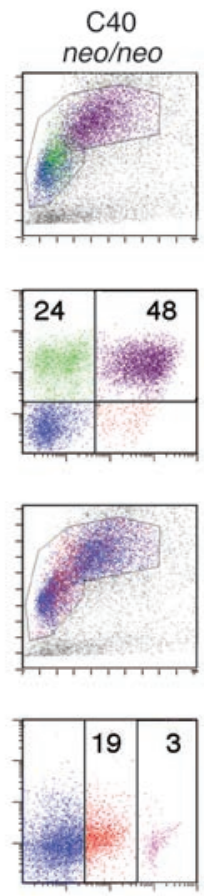

B
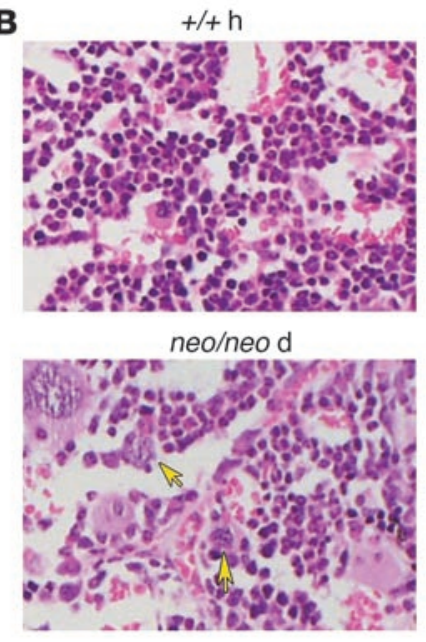

C

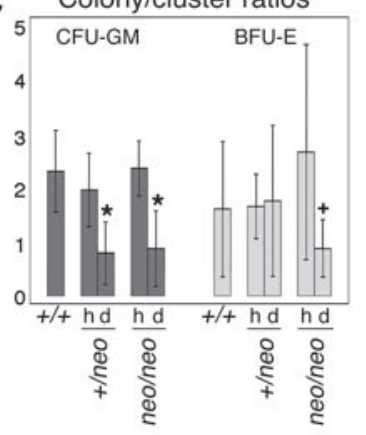

Figure 5

Bone marrow of affected Dido ${ }^{+/ \text {neo }}$ and Dido neo/neo mice displays heterogeneous lesions. (A) Flow cytometry analysis of cells isolated from bone marrow of WT (C38) and 2 representative diseased Dido ${ }^{\text {neo/neo }}$ mice (C28 and C40) stained with mAbs against CD11b, Gr-1, Ter119, and control antigens. FSC versus SSC, CD11b versus $\mathrm{Gr}-1$, and Ter119 versus control dot plots are shown. Numbers in boxes indicate percentages of cells within each gate. (B) Bone marrow sections from WT and diseased Didoneo/neo mice were H\&E stained. Note cells with atypical nuclei (arrows). Magnification, $\times 20$. (C) The colony/cluster ratio is shown for granulocyte-macrophage and erythrocyte bone marrow progenitors from WT mice as well as from healthy and diseased Dido+/neo and Didoneo/neo mice. ${ }^{*} P<0.006 ;+P<0.02$.

Expression levels of $b$ Dido transcripts appeared to be normal in all CLL patients (Table 3).

\section{Discussion}

MDS/MPDs are a group of disorders whose features overlap those of CMPDs and MDSs and are thus difficult to assign to either group. The etiology and molecular basis of MDS/MPDs remain unknown. Clinical and laboratory findings can fall within a continuum ranging from those associated with MDSs to those found with CMPDs. Laboratory findings for Dido-tar-

hDido expression alterations in human myeloid disorders. Targeting of murine Dido caused a disease similar to human MDS/MPDs. We used real-time quantitative PCR to compare hDido1, hDido2, and bDido3 mRNA expression in hematopoietic bone marrow cells from healthy donors with that of patients diagnosed with distinct malignant hematological diseases, including various forms of myeloid disorders. Actin was used to normalize cDNA performance. The relative amounts of $b$ Dido1, $b$ Dido2, and $b$ Dido 3 were estimated as increments in cycle threshold $(\mathrm{Ct})$, which indicated $\mathrm{Ct}$ differences between samples from a pool of 7 healthy donors and those from patients with MDSs, CMPDs, and MDS/MPDs (Figure 7A). We found reduced expression of the 3 bDido transcripts in some patients (such as 5, 15, 24 , and 25), reduced $h$ Dido2 and $h D i d o 3$ but not $h$ Dido 1 expression in others (such as $2,17,26$, and 30 ), and relatively normal expression levels in still others (such as 6, 7,12, and 23) (Figure 7A). Northern blot was also used to assess $h$ Dido expression levels when sufficient RNA was available. Patients 6 and 12 expressed bDido isoforms at normal levels, patient 17 showed only the $b$ Dido 1 isoform, and $b D i d o$ isoforms were undetectable or almost undetectable in patients 15 , 24 , and 25 (Figure 7B). These data coincided with and validated those obtained by quantitative PCR.

In all, 6 of $6 \mathrm{MDS} / \mathrm{MPD}, 7$ of $11 \mathrm{MDS}$, and 7 of $11 \mathrm{CMPD}$ patients showed either reduced expression of the 3 bDido transcripts or reduced bDido 2 and bDido 3 but not hDido 1 expression levels (Table 3). Similar studies were performed using bone marrow samples from healthy donors and from patients diagnosed with AML and chronic lymphocytic leukemia (CLL). In PCR and Northern blot analysis, 3 of 9 AML patients showed clearly reduced bDido2 and bDido3 expression but normal hDido1 levels (Table 3). geted mice are similarly difficult to assign to any of the murine nonlymphoid hematopoietic neoplasm categories proposed to date, which include nonlymphoid leukemias, nonlymphoid hematopoietic sarcomas, myeloid dysplasias, and myeloid proliferation (18). The disease developed by Dido-targeted mice has features of both myeloid dysplasias and myeloid proliferation and is therefore similar to MDS/MPDs. We found no CLL patients with abnormal bDido expression and no Dido-targeted mice with lymphocytosis. Instead, these mice showed increased myeloid cell numbers in marrow and spleen, which occasionally resulted in augmented

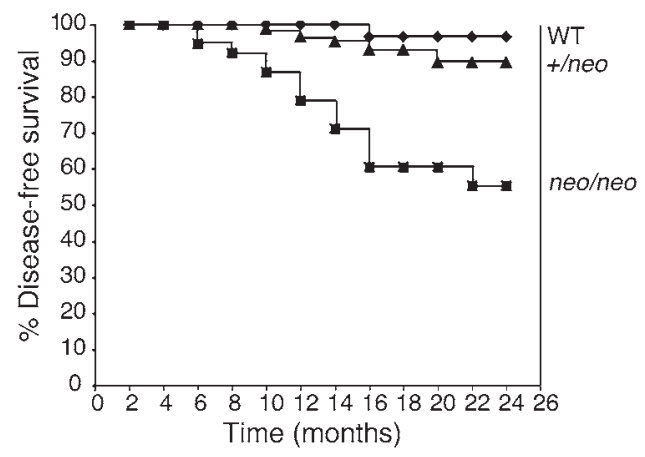

\section{Figure 6}

Targeting mDido causes MDS/MPDs in mice. Mice showing 3 or more spleen or bone marrow symptoms were diagnosed with MDS/MPDs. Percentages of surviving, disease-free mice are shown as Kaplan-Meier curves for WT $(n=30)$, Dido+/neo $(n=86)$, and Dido ${ }^{\text {neo/neo }}(n=38)$ mice. 


\section{Table 2}

Targeting of murine Dido causes a transplantable disease

\begin{tabular}{|c|c|c|c|c|c|c|c|c|c|c|c|}
\hline \multirow[b]{3}{*}{ Recipient mice } & \multicolumn{11}{|c|}{ Donor mice } \\
\hline & \multicolumn{5}{|c|}{$+/+$} & \multicolumn{6}{|c|}{ neo/neo } \\
\hline & A1 & A2 & B1 & E1 & E2 & C1 & C2 & D1 & D2 & F1 & F2 \\
\hline \multicolumn{12}{|l|}{ Bone marrow } \\
\hline \multirow[t]{2}{*}{ Low colony formation ${ }^{A}$} & 3.1 & 2.7 & 4.1 & 4.2 & 2.9 & 1.2 & 1.5 & 1.0 & 0.9 & 1.7 & 1.8 \\
\hline & 2.6 & 1.8 & 2.2 & 2.3 & 1.6 & 1.1 & 1.5 & 1.1 & 0.9 & 1.2 & 1.4 \\
\hline Monocytosis ${ }^{B}$ & 1.7 & 1.7 & 1.3 & 1.1 & 1.3 & 0.9 & 1.4 & 1.4 & 1.5 & 2.8 & 2.5 \\
\hline Granulocytosis ${ }^{\mathrm{C}}$ & 32.8 & 30.7 & 50.1 & 39.6 & 56.5 & 36.3 & 32.7 & 61.9 & 56.0 & 65.9 & 78.1 \\
\hline Ab. erythropoiesis ${ }^{D}$ & 44.5 & 42.4 & 25.8 & 35.8 & 29.0 & 51.5 & 53.2 & 24.7 & 24.5 & 19.3 & 9.3 \\
\hline \multicolumn{12}{|l|}{ Spleen } \\
\hline Splenomegaly E & 0.13 & 0.10 & 0.08 & 0.05 & 0.09 & 0.27 & 0.21 & 0.12 & 0.08 & 0.10 & 0.06 \\
\hline Monocytosis ${ }^{B}$ & 4.9 & 4.4 & 2.2 & 7.9 & 4.2 & 0.8 & 2.2 & 3.9 & 3.5 & 4.0 & 4.8 \\
\hline Granulocytosis ${ }^{C}$ & 8.3 & 6.9 & 14.5 & 15.6 & 36.6 & 10.1 & 5.3 & 47.2 & 47.7 & 42.5 & 85.6 \\
\hline ErythrocytosisF & 40.3 & 9.7 & 37.4 & 18.3 & 24.8 & 84.2 & 79.6 & 22.7 & 33.3 & 38.9 & 2.8 \\
\hline \multicolumn{12}{|l|}{ Blood } \\
\hline \multirow[t]{2}{*}{ Anemia ${ }^{G}$} & 9.3 & 11.9 & 13.4 & 11.3 & 11.8 & 4.7 & 5.6 & ND & 12.4 & 11.3 & 9.9 \\
\hline & 126 & 148 & 157 & 146 & 143 & 67 & 89 & ND & 156 & 133 & 112 \\
\hline Monocytosis ${ }^{H}$ & 0.1 & 0.8 & 0.1 & 1.4 & 0.2 & 0.4 & 0.2 & ND & 1.5 & 0.5 & 1.1 \\
\hline Granulocytosis ${ }^{H}$ & 3.1 & 1.2 & 3.4 & 3.8 & 2.1 & 2.8 & 3.0 & ND & 12.0 & 2.6 & 8.3 \\
\hline
\end{tabular}

Bone marrow cells from healthy WT (+/+) or diseased Didoneo/neo (neo/neo) mice were transplanted into lethally irradiated Dido ${ }^{+/+}$mice. A total of 4 of 9 WT cell recipients and 3 of 9 Dido ${ }^{\text {neo/neo }}$ cell recipients died shortly after transplant. Bone marrow, spleen, and blood from surviving mice were analyzed 5 weeks (B1, D1, D2, E1, E2, F1, and F2 mice) or 10 weeks (A1, A2, C1, and C2 mice) after transplant. ND, not determined. A-HSee Table 1 legend. Red and blue values, which indicate lesions in each mouse, denote severity and mildness of symptoms, respectively.

numbers of circulating cells and enlarged spleens, symptoms compatible with nonlymphoid leukemias, myeloid proliferation, and MDS/MPDs. We ruled out nonlymphoid leukemias, since the percentage of blast cells in blood and bone marrow is always higher in leukemias (> $20 \%$ of all nucleated cells) than that observed in the Dido-targeted mice. Diseased mice were often anemic, and a large number of their spleen and bone marrow cells had atypical nuclei (both symptoms compatible with a diagnosis of myeloid dysplasia or MDS/MPDs). In addition, granulocyte-macrophage and erythroid progenitors showed decreased colony formation accompanied by increased cluster formation potential, a pattern used to diagnose MDSs (11) and MDS/MPDs $(9,10)$. Altogether, these findings in affected Dido-targeted mice suggest that the disease is similar to human MDS/MPDs.

We are unaware of other reports to date of animal models for MDS/MPDs. A few murine models have been developed for CMPDs, by expression of a mutant K-ras ${ }^{\mathrm{G} 12 \mathrm{D}}$ protein from the endogenous locus (24), by germline or somatic inactivation of Nf1 in hematopoietic cells $(27,29,30)$, or by expression of the oncogenic fusion gene AML1-ETO $(31,32)$. None of these mice can be considered MDS/MPD models; although they develop progressive myeloid proliferation, they show no evidence of dysplasia. Signal-induced proliferation-associated gene 1-deficient (SPA-1-deficient) mice develop CML in chronic phase, CML in blast crisis, or MDSs, although none of these mice shows a mixed proliferative and dysplastic phenotype (25). A murine model for MDSs was also developed recently by constitutively expressing EVI1 in bone marrow cells (33). Notably, these mice do not show myeloproliferative symptoms.

Tumor suppressor genes can be inactivated during tumorigenesis through different mechanisms, including loss of expression, acquisition of inactivating mutations, or acquisition of mutations that make the protein gain a new function or work in a dominant-negative fashion. Our data indicate that $100 \%$ of
MDS/MPD patients, $64 \%$ of MDS and CMPD patients, and $33 \%$ of AML patients showed clear loss of hDido expression. Although the number of patients examined is relatively small, our data suggest that hDido expression alterations might be associated with myeloid neoplasms more frequently than is any other known genetic lesion. Less than $40 \%$ of CMML and less than $20 \%$ of JMML patients have point mutations in Ras genes at diagnosis or in the course of disease $(34,35)$, less than $30 \%$ of JMML patients show NF1 gene abnormalities $(36,37)$, and only some JMML patients have PTPN11 mutations (38). The percentage of individuals with myeloid disorders displaying abnormal bDido activity would be even higher if $b$ Dido gene lesions that are undetectable in our assays (i.e., point mutations) were present in patients with normal bDido expression levels. We have begun sequencing hDido cDNA from patients diagnosed with myeloid neoplasms who showed relatively normal $b$ Dido expression levels; at least 1 contained a 143 -bp insertion that caused a frameshift and led to premature translation termination (our unpublished observations).

The percentage of Dido-targeted mice with MDS/MPD symptoms was nonetheless lower than that of patients with $h D i d o$ alterations, and a gene dosage effect was apparent. A dosage effect in tumorigenicity (haploinsufficiency) has been shown for a number of tumor suppressor genes $(39,40)$. Lower penetrance in mice than in humans could be attributed to variation between these 2 species, including distinct genetic requirements for aberrant proliferation, differential expression of tumor suppressor genes, or uncharacterized differences. Examples of these variations have been detailed in the case, for example, of retinoblastoma tumors and the retinoblastoma gene $(r b)$. The $R B$ gene was initially identified as a locus associated with retinoblastoma development (41). Although individuals who inherit 1 mutant $R B$ allele develop this tumor with nearly $100 \%$ probability, $r b^{+/-}$mice develop pituitary and thyroid tumors but not retinoblastoma (42). 
A

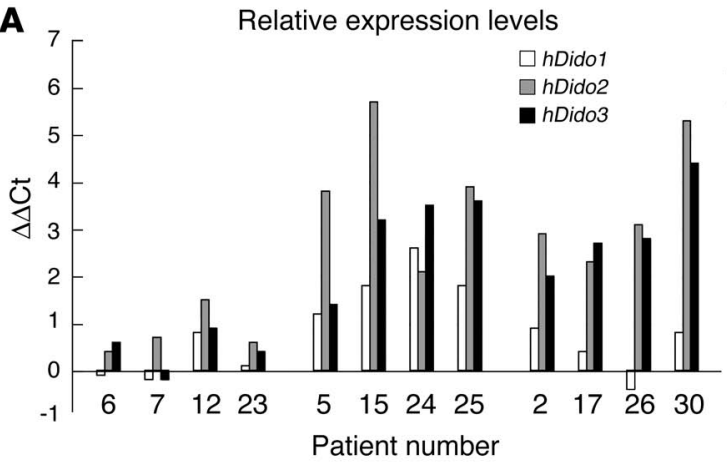

B

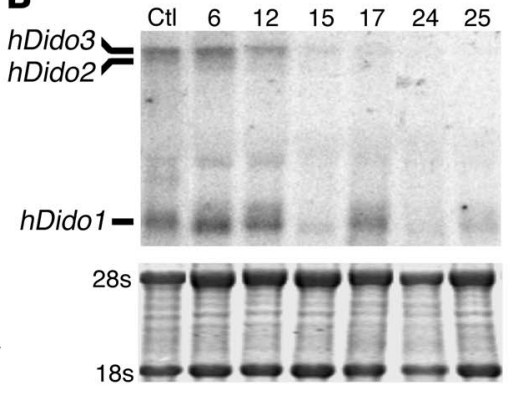

Figure 7

Severe reduction in $h$ Dido expression in bone marrow from MDS/MPD, MDS, and CMPD patients. (A) Relative $h$ Dido1, $h$ Dido2, and $h$ Dido3 expression levels were determined by real-time quantitative PCR. Ct increments relative to those of samples from a pool of healthy donors and actin $(\Delta \Delta \mathrm{Ct})$ are shown for indicated patients. Note that a value of 3 in Ct increments indicates a 10-fold decrease in expression. (B) Northern blot analysis of $h$ Dido1, $h$ Dido2, and $h$ Dido3 expression in bone marrow samples of a healthy control donor $(\mathrm{Ctl})$ and patients, indicated by numbers, diagnosed with various myeloid disorders. The blot was stained with methylene blue to control RNA loading. Positions of $h$ Dido transcripts and $28 \mathrm{~s}$ and 18s RNA are indicated. Diagnosis of patients was as follows: chronic myelomonocytic leukemia (MDS/MPD), patients 15, 24, 25; refractory anemia (MDS), patients 2, 12, 17, 26, 30; polycythemia vera (CMPD), patients 7, 30; essential thrombocythemia (CMPD), patient 6 ; and refractory anemia with ringed sideroblasts (MDS), patient 23.

Although the mechanism of MDS/MPD pathogenesis remains unknown, several recurring clonal cytogenetic abnormalities are found in MDS/MPD patients. Deletion of the long arm of chromosome 20 is the most common structural abnormality in myeloid malignancies, although it is rarely seen in lymphoid neoplasms (20). Karyotypic analysis showed that 1 patient in this study diagnosed with MDS/MPDs had a deletion within 20q12 (our unpublished observations). Karyotypic analysis only detects large chromosomal aberrations; other patients might thus have small deletions affecting 20q. This genetic lesion is proposed to elicit loss of 1 or more unidentified tumor suppressor genes $(21,43)$. We report that the $h D i d o$ locus was found within this region and that its expression was reduced in all MDS/MPD patients studied and most of those with MDSs alone or CMPDs, as compared with controls. Furthermore, we show data suggesting that Dido gene alterations contribute to myeloid but not to lymphoid tumor formation in mice. We speculate that bDido is a gene on this chromosome whose loss could increase susceptibility to myeloid malignancies. As tumors arise after a latency period of several months, additional genetic changes are probably necessary for tumorigenic conversion of Dido-targeted cells. Long latency periods are also reported for development of myeloproliferative diseases in SPA-1- or ICSBP-deficient mice and in mice bearing the onco-
Table 3

hDido expression abnomalities in myeloid neoplasms

\begin{tabular}{|c|c|c|c|}
\hline \multicolumn{4}{|c|}{ Patients showing the indicated hDido expression abnormalities $\left(\mathrm{n}^{\circ}\right)$} \\
\hline Patient group & $\begin{array}{l}\text { Reduced hDido1 } \\
\text { Reduced hDido2 } \\
\text { Reduced hDido3 }\end{array}$ & $\begin{array}{c}\text { Normal hDido1 } \\
\text { Reduced hDido2 } \\
\text { Reduced hDido3 }\end{array}$ & $\begin{array}{l}\text { Total patients with } \\
\text { hDido expression } \\
\text { abnormalities (\%) }\end{array}$ \\
\hline MDS/MPDs & 3 of 6 & 3 of 6 & 100 \\
\hline MDSs & 1 of 11 & 6 of 11 & 64 \\
\hline CMPDs & 3 of 11 & 4 of 11 & 64 \\
\hline AML & 0 of 9 & 3 of 9 & 33 \\
\hline CLL & 0 of 13 & 0 of 13 & 0 \\
\hline Control BM & 0 of 8 & 0 of 8 & 0 \\
\hline
\end{tabular}

hDido1, $h$ Dido2, and $h$ Dido3 expression levels were analyzed by real-time quantitative PCR and Northern blot in bone marrow samples from healthy donors (control BM, $n=8)$ and patients diagnosed with MDS/MPD $(n=6)$, MDS $(n=11)$, CMPDs $(n=11)$, AML $(n=9)$, and CLL $(n=13)$. The number of patients showing either reduced $h D i d o 1, h D i d o 2$, and $h$ Dido3 expression or reduced $h$ Dido2 and $h$ Dido3 but relatively normal $h$ Dido1 expression levels is shown. The total percentage of patients tested who showed some type of $h$ Dido expression abnormality is indicated in the right column. $\mathrm{n}^{\circ}$, number of patients. genic fusion gene AML1-ETO (25, $31,32,44)$. The possible cooperation of Dido deficiency with other genetic alterations is currently under study.

Since many patients diagnosed with myeloid neoplasms show reduced $b D i d o 2$ and $h D i d o 3$ but normal $b$ Dido1 levels, we propose that inactivation of $b D i d o 2$ and hDido3 but not of $h D i d o 1$ might be involved in the formation of these tumors. To confirm this hypothesis, we are currently targeting exons shared by murine Dido2 and Dido3. In contrast, many human and murine cell lines of other origins show reduced Dido1 but relatively normal Dido2 and Dido3 levels. These data suggest that loss of Dido2 and/or Dido3 might be specific to myeloid tumors. The decrease in hDido 2 and hDido 3 in these patients is probably not due to variability in bone marrow cell composition, since in vitro-cultured murine bone marrow erythrocyte, granulocyte-monocyte, and B lymphocyte precursors express similar mDido1, mDido2, and mDido3 levels (our unpublished observations). Preferential loss of certain Dido isoforms could be explained by neoplasia-associated splicing aberrations or differences in mRNA stability.

As Dido1 was previously implicated in early onset of apoptosis (28), we looked for increased or decreased apoptosis in several tissues and systems in Dido-targeted mice but found no differences among genotypes (our unpublished observations). It is nonetheless possible that single targeting of $m D i d o 1$ had an effect on apoptosis; alternatively, cell lineage or developmental stage may play a in Dido-induced apoptosis. Dido2 or Dido3 overexpression in different cell types did not induce cell death (our unpublished observations); these proteins may instead be involved in genomic 
stabilization. We recently found that mDido3 localizes to the meiotic synaptonemal central element and contacts chromatin structures by direct binding to histones. The Dido common $\mathrm{N}$ terminal domain mediates histone interaction, which suggests that Dido1 and Dido2 also bind directly to histones. The truncated mDido3 protein in Dido-targeted mice lacks the $\mathrm{N}$ terminal region and cannot interact with histones (van Wely et al., unpublished observations). The presence of this truncated Dido3 form in the mutant mice raises the possibility that their hematopoietic phenotype could be attributed to loss-of-function, dominant-negative, or gain-of-function effects exerted by the mutant protein. Although we cannot definitively rule out any of these possibilities, we believe that loss of function probably accounts for MDS/ MPD development in mice since loss of function was identified in truncated mDido3 (histone binding) and loss of hDido function (by loss of expression) was found in all MDS/MPD and most CMPD, MDS, and AML patients analyzed. As a dominant-negative mutation can be even more disruptive to normal cell function than a null mutation (45), we would expect the penetrance of a dominant-negative mutant in heterozygosity to be at least as high as that of a nullizygous mouse.

Compared with hematopoietic progenitors from WT mice, those from most diseased Dido-targeted mice show decreased colony but increased cluster formation potential. This resembles a pattern associated with MDS and MDS/MPD patients, which is characterized by increased micro- and macrocluster formation, defective colony maturation, and a decrease in or lack of colony formation (9-11). The meaning of this growth pattern is unknown, but it might indicate cell growth conditions that facilitate a hyperproliferative state since it correlates positively with increased risk of leukemic transformation $(46,47)$. Although the exact mechanism underlying the anomalies in MDS/MPD and MDS patients has not been identified, these defects are postulated to reflect an imbalance between cell proliferation and differentiation, as well as increased apoptosis.

Dido-targeted mice develop a disease similar to MDS/MPDs after a 7-to 8-month latency period, suggesting that additional genetic lesions are required. Once Dido-targeted cells accumulate these lesions and are transformed, they develop disease, as shown in our cell transfer experiments. These results could be explained by a role in genomic stabilization for Dido, as its loss of function would facilitate induction of additional genetic lesions affecting distinct proliferation, differentiation, or survival pathways. In this model, Dido ${ }^{+/ n e o}$ mice, which express lower levels of fully functional $\mathrm{mDido} 3$ than WT animals, may be subject to an intermediate degree of genomic destabilization, between that of WT and Didoneo/neo mice, and thus to lower tumor penetrance than Didoneo/neo mice. Loss of heterozygosity would not be necessary for tumor formation in heterozygous mice. Our findings suggest that Dido might be one of the tumor suppressor genes at chromosome $20 \mathrm{q}$ and that the Dido-targeted mouse may be a suitable model for studying MDS/MPDs and testing new approaches to their diagnosis and treatment.

\section{Methods}

Cloning of Dido2 and Dido3. Complete $h D i d o 2$ - and $h D i d o 3$-specific sequences were obtained by 3 '-RACE (using the 3 '-RACE system, Invitrogen Corp.) and confirmed by matching to sequences from NCBI and Celera nucleotide databases. Human and mouse full-length Dido2 and Dido3 were generated by RT-PCR using forward primers upstream of the Dido1 start codon and reverse primers downstream of the Dido2 or Dido3 stop codons. Full-length cDNAs were cloned into pcDNA3 in frame with a Flag tag.

Generation of Dido-targeted mice. The mDido targeting vector was derived from the pPNT vector (48). The 5' homology short arm (950 bp) was generated by PCR on a bacterial artificial chromosome (BAC) clone containing all $m$ Dido1 exons. The $3^{\prime}$ homology long arm (6 kbp) was a BglII/EcoRI fragment from the same BAC clone. The targeting vector contained a pGKneo resistance cassette between the $5^{\prime}$ and $3^{\prime}$ homology arms and an HSV-tk cassette downstream of the $3^{\prime}$ homology arm. R1 ES cells (49) were electroporated with the vector; G418- and gancyclovir-resistant ES cell clones were isolated and analyzed by PCR and Southern blot. A 5'-flanking probe on EcoRV-digested genomic DNA produced a 7-kb WT band and a $5.5-\mathrm{kb}$ mutant band. Single integration of the targeting vector was verified by Southern blot with the neoresistance cassette. Chimeric mice were generated by morula aggregation of CD1 mice with targeted ES cell clones. Germline transmission was obtained from 2 independent ES cell clones, and mice were bred to homozygosis. We found no obvious differences between mice derived from independent clones. All experiments were performed with the F1 generation on a mixed CD1 and J129/sv background. Littermates were used as controls. All animal procedures were approved by the Centro Nacional de Biotecnología Animal Care and Use Committee. PCR primer sequences are available on request.

Cells. R1 ES cells were maintained in DMEM medium (Gibco; Invitrogen Corp.) with $20 \% \mathrm{FCS}$, nonessential amino acids, $50 \mu \mathrm{M}$ 2-ME, $100 \mathrm{U} / \mathrm{ml}$ penicillin, $100 \mu \mathrm{g} / \mathrm{ml}$ streptomycin, and $1000 \mathrm{U} / \mathrm{ml}$ murine leukemia inhibitory factor (Chemicon International). All other cell lines (except 293T, NIH-3T3, mouse embryonic fibroblasts [MEFs], HeLa, and HCT15) were cultured in RPMI 1640 (Gibco; Invitrogen Corp.) with 10\% FCS, $2 \mathrm{mM}$ glutamine, $100 \mathrm{U} / \mathrm{ml}$ penicillin, and $100 \mu \mathrm{g} / \mathrm{ml}$ streptomycin. Growth medium for FL5.12 cells was supplemented with 5\% WEHI cellconditioned medium (as an IL-3 source); growth medium for CTLL-2, B6.1, and AE7 cell lines was supplemented with 5\% X63 cell-conditioned medium (as an IL-2 source). Human embryonic kidney 293 T cells, NIH-3T3 cells, and MEFs were cultured in DMEM with 10\% FCS, 2 mM glutamine, $100 \mathrm{U} / \mathrm{ml}$ penicillin, and $100 \mu \mathrm{g} / \mathrm{ml}$ streptomycin. To obtain mouse bone marrow hematopoietic cells, marrow was flushed from femurs with culture medium. Splenocytes were isolated and suspended in culture medium. Blood was drawn from the heart, immediately placed into EDTA-containing tubes, and mixed thoroughly. Complete blood counts were performed using an MS-9 hematocytometer (Kémia).

Human bone marrow samples were obtained from healthy donors or from patients diagnosed with an MDS/MPD (chronic myelomonocytic leukemia), MDSs (refractory anemia, refractory anemia with ringed sideroblasts, and refractory anemia with excess blasts), CMPDs (chronic myelogenous leukemia, polycythemia vera, essential thrombocythemia, chronic idiopathic myelofibrosis, and CMPD-unclassifiable), AML, or CLL. The Hospital Universitario de Salamanca institutional review board approved these studies. Informed consent was obtained from all individuals or their parents.

Northern blot analysis. Total RNA was prepared as described (50). RNA (20 $\mu \mathrm{g})$ was analyzed by Northern blot and probed using a ${ }^{32}$ P-labeled 5' DNA fragment common to all Dido transcripts. Hybridization was performed at $65^{\circ} \mathrm{C}$; washes were in $2 \times \mathrm{SSC}+0.5 \%$ SDS followed by $0.2 \times \mathrm{SSC}+0.5 \% \mathrm{SDS}$ at $65^{\circ} \mathrm{C}$. Bands were detected with a Phosphorimager (Molecular Dynamics). Membranes were stained with methylene blue to visualize $28 \mathrm{~s}$ and $18 \mathrm{~s}$ RNA as loading references.

Immunoblot and immunohistochemistry. 293T cells were transiently transfected with FuGene (Roche Diagnostics Corp.) following manufacturer's protocol. Cell extracts were prepared in loading buffer and boiled; after $8 \%$ SDS-PAGE, proteins were transferred to nitrocellulose membranes (BioRad Laboratories). Protein loading equivalence was verified by ponceau red 
(Sigma-Aldrich) staining. The membrane was probed with the M2 anti-Flag $\mathrm{mAb}$ (Sigma-Aldrich), followed by peroxidase-anti-mouse polyclonal $\mathrm{Ab}$ (DakoCytomation). Chemiluminescent detection reagent (ECL, Amersham Biosciences) was used and the membrane exposed to Kodak X-Omat film. Paraffin-embedded spleen sections $(4 \mu \mathrm{m})$ were labeled with biotin-antiB220 mAb (SouthernBiotech) followed by StreptABComplex/HRP (DakoCytomation). Slides were hematoxylin counterstained.

Flow cytometry analysis. Bone marrow and spleen single-cell suspensions were stained with combinations of FITC-conjugated anti-CD11b and PEconjugated anti-Gr-1 Ab or FITC-control and biotin-anti-Ter119 Ab plus Streptavidin-PE (all from BD Biosciences - Pharmingen). Analysis was performed using a Coulter EPICS XL cytometer and Coulter EXPO32 ADC version 1.1 software (Beckman Coulter).

Colony-formation assays. Granulocyte-macrophage progenitors (CFU-GM) in bone marrow samples were assessed by culturing $10^{5}$ cells $/ \mathrm{ml}$ in methylcellulose medium containing recombinant cytokines (MethoCult M3534; StemCell Technologies). Cytokine-free medium (MethoCult M3234; StemCell Technologies) was supplemented with $6 \mathrm{U} / \mathrm{ml}$ erythropoietin (NeoRecormon; Roche Diagnostics Corp.), $50 \mathrm{ng} / \mathrm{ml}$ murine stem cell factor (PeproTech), and 15\% conditioned WEHI medium (as IL-3 source) to assess erythroid progenitors (BFU-E). Colonies ( $>100$ cells) and clusters $(<100$ cells) were counted in 2 independent plates incubated for 7 to 8 days (CFU$\mathrm{GM}$ ) or 9 days (BFU-E) at $37^{\circ} \mathrm{C}$ in $5 \% \mathrm{CO}_{2}$.

Cell transfer experiments. At 4 to 5 weeks of age, recipient mice were lethally irradiated ( $8 \mathrm{~Gy}$ ) and immediately inoculated with $2 \times 10^{6}$ donor marrow mononuclear cells via the dorsal tail vein. All surviving recipients were sacrificed and screened for MDS/MPD symptoms 5-10 weeks after transfer.

Real-time quantitative PCR analysis. DNase I-digested total RNA was reverse-transcribed with Superscript II (Invitrogen Corp.) following manufacturer's instructions. For quantitative Taqman (Applied Biosystems) PCR analysis, regions specific to actin (Applied Biosystems), hDido1, hDido2, and hDido3 were amplified with specific primers for 40 cycles, monitored with a carboxyfluorescein-aminohexyl amidite-labeled (FAMlabeled) probe in an ABI Prism 7700 Sequence Detector, then analyzed with the Sequence Detection System, version 1.9.1 (Applied Biosystems). Two independent dilutions of each sample were tested in duplicate. The PCR primer and probe sequences used include: human $\beta$-actin (Applied Biosystems), hDido1 (forward CCTCGCCGTCACTGTTGT and reverse GGTCCAGGAGGCCAACC, FAM-labeled probe CCTAGGTGATACATACATTTAT), $b$ Dido 2 (forward TTCCATCCAAACTCTTGCCCTTT, reverse CCTCACCTCCACCCAGAAAG, FAM-labeled probe CCGGCGCTTACCTGGT), and bDido3 (forward TTCCATCCAAACTCTTGCCCTTT, reverse CCAAGAATTATATTCGGACGTGGTG, FAM-labeled probe ACTCAAGACCTGGTCCCTC). Primer efficiencies were calculated and found to be equivalent. For each sample, the amount of hDido1, hDido2, and bDido3 relative to that of actin was estimated according to the $\mathrm{Ct}$, which defines the PCR cycle number at which the PCR signal reaches a defined value. The relative amount of $h$ Dido isoforms was estimated as the Ct increment that represents $\mathrm{Ct}$ differences between a pool of 7 healthy donors and patients $(\Delta \Delta \mathrm{Ct})$.

Accession numbers. GenBank accession number AY425951 was assigned to mDido2, AY425952 to mDido3, AY481571 to bDido2, and AY481572 to bDido3.

Statistical analysis. Data were evaluated using an unpaired Student's $t$ test, when 2 conditions were compared. $P$ values of less than 0.05 were considered statistically significant.

\section{Acknowledgments}

We thank I. Moreno de Alborán for discussion and advice; the Centro Nacional de Biotecnología Animal Facility for support; A. Zaballos for help with quantitative RT-PCR assays; C. Mark for editorial assistance; and I. Moreno de Alborán and K. Van Wely for critical reading of the manuscript. M.R. Campanero was supported by the Spanish Council for Scientific Research (CSIC), the Spanish Ministry of Health (C03/10), and the Spanish Ministry of Education (BMC2001-1738). This work was funded by grants from the European Union, the Spanish Ministry of Health, and the Spanish Ministry of Education and Science. The Department of Immunology and Oncology was founded and is supported by the Consejo Superior de Investigaciones Cientifícas and by Pfizer Inc.

Received for publication December 13, 2004, and accepted in revised form June 21, 2005.

Address correspondence to: Carlos Martínez-A, Department of Immunology and Oncology, Centro Nacional de Biotecnología, Darwin 3, Campus de Cantoblanco, Madrid, E-28049, Spain. Phone: 34-91-585-4537; Fax: 34-91-372-0493; E-mail: cmartineza@cnb. uam.es. Or to: Miguel R. Campanero, Instituto de Investigaciones Biomédicas, Consejo Superior de Investigaciones Cientifícas-Universidad Autónoma de Madrid, Madrid, Spain. Phone: 34-91-5854490; Fax: 34-91-585-4401; E-mail: mcampanero@iib.uam.es.

Agnes Fütterer and Miguel R. Campanero contributed equally to this work.
1. Van Etten, R.A., and Shannon, K.M. 2004. Focus on myeloproliferative diseases and myelodysplastic syndromes. Cancer Cell. 6:547-552.

2. Vardiman, J.W., Harris, N.L., and Brunning, R.D. 2002. The World Health Organization (WHO) classification of the myeloid neoplasms. Blood. 100:2292-2302.

3. Greenberg, P.L., Young, N.S., and Gattermann, N. 2002. Myelodysplastic syndromes [review]. Hematology (Am. Soc. Hematol. Educ. Program). 2002:136-161.

4. Dickstein, J.I., and Vardiman, J.W. 1995. Hematopathologic findings in the myeloproliferative disorders. Semin. Oncol. 22:355-373.

5. Imbert, M. 2002. Peripheral blood findings in chronic myeloproliferative disorders. Clin. Lab. Med. 22:137-151.

6. Stewart, K., Carstairs, K.C., Dube, I.D., and Keating, A. 1990. Neutrophilic myelofibrosis presenting as Philadelphia chromosome negative BCR non-rearranged chronic myeloid leukemia. Am. J. Hematol. 34:59-63.

7. Thiele, J., Fohlmeister, I., Vonneguth, B., Zankov- ich, R., and Fischer, R. 1986. The prognostic implication of clinical and histological features in Ph1+ chronic myelocytic leukaemia (CML). Anticancer Res. 6:1401-1409.

8. Arceci, R.J., Longley, B.J., and Emanuel, P.D. 2002. Atypical cellular disorders [review]. Hematology (Am. Soc. Hematol. Educ. Program). 2002:297-314.

9. Del Canizo, M.C., et al. 1998. The value of cell cultures for the diagnosis of mixed myelodysplastic/ myeloproliferative disorders. Haematologica. 83:3-7.

10. Neuwirtova, R., et al. 1996. Mixed myelodysplastic and myeloproliferative syndromes. Leuk. Res. 20:717-726.

11. Shih, L.Y., Chiu, W.F., and Lee, C.T. 1991. Diagnostic and prognostic values of in vitro culture growth patterns of marrow granulocyte-macrophage progenitors in patients with myelodysplastic syndrome. Lenkemia. 5:1092-1098.

12. Mesa, R.A. 2002. Clinical and scientific advances in the Philadelphia-chromosome negative chronic myeloprolferative disorders. Int. J. Hematol. 76(Suppl. 2):193-203.
13. Steensma, D.P., Tefferi, A., and Li, C.Y. 2003. Splenic histopathological patterns in chronic myelomonocytic leukemia with clinical correlations: reinforcement of the heterogeneity of the syndrome. Leuk. Res. 27:775-782.

14. Foa, P., et al. 1991. Chronic neutrophilic leukaemia associated with polycythemia vera: pathogenetic implications and therapeutic approach. Br.J. Haematol. 78:286-288.

15. Ohyashiki, K., et al. 1993. Myelodysplastic syndrome evolving into a myeloproliferative disorder: one disease or two? Lenkemia. 7:338-340.

16. Shamdas, G.J., Spier, C.M., and List, A.F. 1991. Myelodysplastic transformation of polycythemia vera: case report and review of the literature [review]. Am. J. Hematol. 37:45-48.

17. Verhoef, G.E., Demuynck, H., Zachee, P., and Boogaerts, M.A. 1994. Myelodysplastic syndrome evolving into a myeloproliferative disorder: one disease or two [review]? Lenkemia. 8:714-715.

18. Kogan, S.C., et al. 2002. Bethesda proposals for classification of nonlymphoid hematopoietic neo- 
plasms in mice. Blood. 100:238-245.

19. Melo, J.V. 1996. The diversity of BCR-ABL fusion proteins and their relationship to leukemia phenotype. Blood. 88:2375-2384.

20. Dewald, G.W., Schad, C.R., Lilla, V.C., and Jalal, S.M. 1993. Frequency and photographs of HGM11 chromosome anomalies in bone marrow samples from 3,996 patients with malignant hematologic neoplasms. Cancer Genet. Cytogenet. 68:60-69.

21. Asimakopoulos, F.A., White, N.J., Nacheva, E., and Green, A.R. 1994. Molecular analysis of chromosome $20 \mathrm{q}$ deletions associated with myeloproliferative disorders and myelodysplastic syndromes. Blood. 84:3086-3094.

22. Mitelman, F., Mertens, F., and Johansson, B. 1997. A breakpoint map of recurrent chromosomal rearrangements in human neoplasia. Nat. Genet. 15:417-474.

23. Davis, M.P., Dewald, G.W., Pierre, R.V., and Hoagland, H.C. 1984. Hematologic manifestations associated with deletions of the long arm of chromosome 20. Cancer Genet. Cytogenet. 12:63-71.

24. Braun, B.S., et al. 2004. Somatic activation of oncogenic Kras in hematopoietic cells initiates a rapidly fatal myeloproliferative disorder. Proc. Natl. Acad. Sci. U. S. A. 101:597-602.

25. Ishida, D., et al. 2003. Myeloproliferative stem cell disorders by deregulated Rap 1 activation in SPA-1deficient mice. Cancer Cell. 4:55-65.

26. Kometani, K., Ishida, D., Hattori, M., and Minato, N. 2004. Rap1 and SPA-1 in hematologic malignancy. Trends Mol. Med. 10:401-408.

27. Le, D.T., et al. 2004. Somatic inactivation of Nf1 in hematopoietic cells results in a progressive myeloproliferative disorder. Blood. 103:4243-4250.

28. Garcia-Domingo, D., et al. 1999. DIO-1 is a gene involved in onset of apoptosis in vitro, whose misexpression disrupts limb development. Proc. Natl. Acad. Sci. U. S. A. 96:7992-7997.

29. Bollag, G., et al. 1996. Loss of NF1 results in acti- vation of the Ras signaling pathway and leads to aberrant growth in haematopoietic cells. Nat. Genet. 12:144-148.

30. Largaespada, D.A., Brannan, C.I., Jenkins, N.A., and Copeland, N.G. 1996. Nf1 deficiency causes Rasmediated granulocyte/macrophage colony stimulating factor hypersensitivity and chronic myeloid leukaemia. Nat. Genet. 12:137-143.

31. Fenske, T.S., et al. 2004. Stem cell expression of the AML1/ETO fusion protein induces a myeloproliferative disorder in mice. Proc. Natl. Acad. Sci. U. S. A. 101:15184-15189.

32. Higuchi, M., et al. 2002. Expression of a conditional AML1-ETO oncogene bypasses embryonic lethality and establishes a murine model of human $\mathrm{t}(8 ; 21)$ acute myeloid leukemia. Cancer Cell. 1:63-74.

33. Buonamici, S., et al. 2004. EVI1 induces myelodysplastic syndrome in mice. J. Clin. Invest. 114:713-719. doi:10.1172/JCI200421716.

34. Miyauchi, J., et al. 1994. Mutations of the N-ras gene in juvenile chronic myelogenous leukemia. Blood. 83:2248-2254.

35. Parker, J., and Mufti, G.J. 1996. Ras and myelodysplasia: lessons from the last decade [review]. Semin. Hematol. 33:206-224.

36. Shannon, K.M., et al. 1994. Loss of the normal NF1 allele from the bone marrow of children with type 1 neurofibromatosis and malignant myeloid disorders. N. Engl. J. Med. 330:597-601.

37. Side, L.E., et al. 1998. Mutations of the NF1 gene in children with juvenile myelomonocytic leukemia without clinical evidence of neurofibromatosis, type 1. Blood. 92:267-272.

38. Tartaglia, M., et al. 2003. Somatic mutations in PTPN11 in juvenile myelomonocytic leukemia, myelodysplastic syndromes and acute myeloid leukemia. Nat. Genet. 34:148-150.

39. Fodde, R., and Smits, R. 2002. Cancer biology. A matter of dosage. Science. 298:761-763.

40. Islam, M.Q., and Islam, K. 2000. A new functional classification of tumor-suppressing genes and its therapeutic implications. Bioessays. 22:274-285.

41. Knudson, A.G., Jr. 1971. Mutation and cancer: statistical study of retinoblastoma. Proc. Natl. Acad. Sci. U. S. A. 68:820-823.

42. Jacks, T., et al. 1992. Effects of an Rb mutation in the mouse. Nature. 359:295-300.

43. White, N.J., et al. 1994. Deletion of chromosome $20 \mathrm{q}$ in myelodysplasia can occur in a multipotent precursor of both myeloid cells and B cells. Blood. 83:2809-2816.

44. Holtschke, T., et al. 1996. Immunodeficiency and chronic myelogenous leukemia-like syndrome in mice with a targeted mutation of the ICSBP gene. Cell. 87:307-317.

45. Paige, A.J. 2003. Redefining tumour suppressor genes: exceptions to the two-hit hypothesis [review]. Cell. Mol. Life Sci. 60:2147-2163.

46. Milner, G.R., et al. 1977. Bone marrow culture studies in refractory cytopenia and 'smouldering leukaemia'. Br. J. Haematol. 35:251-261.

47. Spitzer, G., Verma, D.S., Dicke, K.A., Smith, T., and McCredie, K.B. 1979. Subgroups of oligoleukemia as identified by in vitro agar culture. Lenk. Res. 3:29-39.

48. Tybulewicz, V.L., Crawford, C.E., Jackson, P.K., Bronson, R.T., and Mulligan, R.C. 1991. Neonatal lethality and lymphopenia in mice with a homozygous disruption of the c-abl proto-oncogene. Cell. 65:1153-1163.

49. Nagy, A., Rossant, J., Nagy, R., Abramow-Newerly, W., and Roder, J.C. 1993. Derivation of completely cell culture-derived mice from early-passage embryonic stem cells. Proc. Natl. Acad. Sci. U. S. A. 90:8424-8428.

50. Sambrook, J., Fritsch, E.F., and Maniatis, T. 1989. Extraction, purification, and analysis of messenger RNA from eukaryotic cells. In Molecular cloning: a laboratory manual. 2nd edition. Cold Spring Harbor Laboratory Press. Cold Spring Harbor, New York, USA. 7.1-7.87. 